\title{
A novel imidazopyridine PI3K inhibitor with anticancer activity in non-small cell lung cancer cells
}

\author{
HYUNSEUNG LEE ${ }^{1 *}$, SOO JUNG KIM ${ }^{1 *}$, KYUNG HEE JUNG ${ }^{1}$, MI KWON SON ${ }^{1}$, \\ HONG HUA YAN ${ }^{1}$, SUNGWOO HONG ${ }^{2}$ and SOON-SUN HONG ${ }^{1}$ \\ ${ }^{1}$ Department of Drug Development, College of Medicine, Inha University, Sinheung-dong, \\ Jung-gu, Incheon 400-712; ${ }^{2}$ Department of Chemistry, Korea Advanced Institute of \\ Science and Technology (KAIST), Daejeon 305-701, Republic of Korea
}

Received March 6, 2013; Accepted May 2, 2013

DOI: $10.3892 / o r .2013 .2499$

\begin{abstract}
Lung cancer is the leading cause of cancer-related mortality in the world, and non-small cell lung cancer (NSCLC) accounts for approximately $85 \%$ of all cases. Since more than $60 \%$ of NSCLC cases express the epidermal growth factor receptor (EGFR), EGFR tyrosine kinase inhibitors are used to treat NSCLC. However, due to the acquired resistance associated with EGFR-targeted therapy, other strategies for the treatment of NSCLC are urgently needed. Therefore, we investigated the anticancer effects of a novel phosphatidylinositol 3-kinase $\alpha(\mathrm{PI} 3 \mathrm{~K} \alpha)$ inhibitor, HS-173, in human NSCLC cell lines. HS-173 demonstrated anti-proliferative effects in NSCLC cells and effectively inhibited the PI3K signaling pathway in a dose-dependent manner. In addition, it induced cell cycle arrest at $\mathrm{G}_{2} / \mathrm{M}$ phase as well as apoptosis. Taken together, our results demonstrate that HS-173 exhibits anticancer activities, including the induction of apoptosis, by blocking the PI3K/Akt/mTOR pathway in human NSCLC cell lines. We, therefore, suggest that this novel drug could potentially be used for targeted NSCLC therapy.
\end{abstract}

\section{Introduction}

Lung cancer is the most common cause of cancer-related mortality in men and the second most common cause in women, resulting in 1.61 million new cases and 1.38 million deaths annually (1). In the treatment of lung cancer, surgery, chemotherapy, radiotherapy, or their combination are selected depending on the histological diagnosis, the stage of the cancer,

Correspondence to: Dr Soon-Sun Hong, Department of Biomedical Sciences, College of Medicine, Inha University, 3-ga, Sinheung-dong, Jung-gu, Incheon 400-712, Republic of Korea

E-mail: hongs@inha.ac.kr

*Contributed equally

Key words: HS-173, phosphatidylinositol 3-kinase inhibitor, anticancer drug, apoptosis, non-small cell lung cancer and the age of the patient. Despite the significant progress that has been made in developing effective treatment strategies and the substantial research efforts undertaken, the prognosis for lung cancer patients remains poor, and the development of more effective treatments is one of the most important topics in the field of oncology. Lung cancer is classified according to histological type: non-small cell lung cancer (NSCLC) and small cell lung cancer (SCLC). Approximately 85-90\% of lung cancers are NSCLC, which is further subdivided into adenocarcinoma (AC), squamous cell carcinoma (SCC), and large cell carcinoma (LCC) (2). While SCLC usually responds better to chemotherapy and radiation, NSCLC is relatively insensitive to both therapeutic modalities (3).

More than $60 \%$ of NSCLC cases overexpress the epidermal growth factor receptor (EGFR), whereas no overexpression is detected in SCLC (4). These receptors play an important role in tumor cell survival, and activated phosphorylated EGFR results in the phosphorylation of downstream proteins that cause cell proliferation, invasion, metastasis and inhibition of apoptosis. Therefore, EGFR tyrosine kinase inhibitors (TKIs), gefitinib and erlotinib, are currently used to treat NSCLC (5). Despite initial responses, patients eventually experience disease progression due to unknown mechanisms of acquired resistance. Acquired resistance of NSCLC to TKIs is thought to be associated with a second mutation in the EGFR kinase domain (6).

Phosphatidylinositol 3-kinase (PI3K) is a key downstream component of the EGFR pathway and plays significant roles in cell survival, proliferation, growth and cytoskeleton rearrangement (7-10). The expression of PI3K has been related to EGFR TKI resistance in preclinical models (11-13). Engelman et al (14) found that expression of the kinase domain mutant H1047R of PI3K $\alpha$ in mouse lung induced ACs in vivo. Mutant PIK3CA has been implicated in the pathogenesis of several types of cancers, including colon cancer, gliomas, gastric cancer, breast cancer, endometrial cancer and lung cancer (15). These mutations can maintain PI3K/Akt/mTOR signaling under conditions of growth factor deprivation and thus transform cells. Therefore, PI3K is a novel target for more effective treatment of NSCLC.

We designed and synthesized a new series of imidazo[1,2a]pyridine derivatives with the goal of developing a novel 
structural class of potent PI3K inhibitors. Among these compounds, HS-173 strongly inhibited PI3K activity (16). In the present study, we investigated the anticancer activity of HS-173 in NSCLC cells through disruption of the PI3K/Akt/ mTOR pathway or inhibition of PI3K activity.

\section{Materials and methods}

Cell lines and reagents. The human NSCLC cell lines (A549, H1299 and NCI-H596) were purchased from the Korean Cell Line Bank (KCLB, Seoul, Republic of Korea). Cells were cultured in Roswell Park Memorial Institute (RPMI)-1640 supplemented with $10 \%$ fetal bovine serum (FBS) and $1 \%$ penicillin/streptomycin. Cell cultures were maintained at $37^{\circ} \mathrm{C}$ in a $\mathrm{CO}_{2}$ incubator. Ethyl 6-(5-(phenylsulfonamido)pyridin3-yl)imidazo[1,2-a]pyridine-3-carboxylate (HS-173) was synthesized according to our previous methods (16). HS-173 was dissolved in dimethyl sulfoxide (DMSO) at a concentration of $10 \mathrm{mM}$ before use. DMSO was added to the cells at $0.1 \%(\mathrm{v} / \mathrm{v})$ as a solvent control.

Cell proliferation assay. The inhibitory effect of HS-173 on NSCLC cell lines was assessed by measuring 3-(4,5-dimethylthiazol-2-yl)-2,5-diphenyltetrazolium bromide (MTT) dye absorbance. Briefly, cells were plated at a density of $3-5 \times 10^{3}$ cells/well in $96-$ well plates for $24 \mathrm{~h}$. The medium was then removed, and cells were treated with either DMSO as a control or various concentrations $(0.1-10 \mu \mathrm{M})$ of HS-173. After the cells were incubated for $48 \mathrm{~h}, 100 \mu \mathrm{l}$ of MTT solution $(2 \mathrm{mg} / \mathrm{ml})$ was added to each well, and the plate was incubated for another $4 \mathrm{~h}$ at $37^{\circ} \mathrm{C}$. The formed formazan crystals were dissolved in DMSO (100 $\mu \mathrm{l} /$ well) with constant shaking for $5 \mathrm{~min}$. The absorbance of the solution was then measured with a microplate reader at $540 \mathrm{~nm}$. This assay was conducted in triplicate.

Cell cycle analysis. A549 cells were plated in 100-mm culture dishes. The next day, the cells were treated with various concentrations of HS-173 for $12 \mathrm{~h}$. Floating and adherent cells were collected and fixed with ice-cold $70 \%$ ethanol at $4^{\circ} \mathrm{C}$ overnight. After washing with PBS, the cells were subsequently stained with $50 \mu \mathrm{g} / \mathrm{ml}$ propidium iodide (PI) and $100 \mu \mathrm{g} / \mathrm{ml} \mathrm{RNase} \mathrm{A}$ for $1 \mathrm{~h}$ in the dark, and then subjected to flow cytometric analysis to determine the percentage of cells in specific phases of the cell cycle (sub- $G_{1}, G_{0} / G_{1}, S$ and $G_{2} / M$ ). Flow cytometric analysis was performed using a FACSCalibur flow cytometer (BD Biosciences, Franklin Lakes, NJ, USA) equipped with a 488-nm argon laser. Flow cytometric data analysis was conducted using FlowJo software (Tree Star, Inc., San Carlos, CA, USA). All the experiments were performed in triplicate.

Western blotting. Total cellular proteins were extracted with lysis buffer containing $1 \%$ Triton X-100, $1 \%$ Nonidet P-40, and the following protease and phosphatase inhibitors: aprotinin $(10 \mathrm{mg} / \mathrm{ml})$, leupeptin $(10 \mathrm{mg} / \mathrm{ml}$; ICN Biomedicals, Asse-Relegem, Belgium), phenylmethylsulfonyl fluoride $(1.72 \mathrm{mM}), \mathrm{NaF}(100 \mathrm{mM}), \mathrm{NaVO}_{3}(500 \mathrm{mM})$, and $\mathrm{Na}_{4} \mathrm{P}_{2} \mathrm{O}_{7}$ $(500 \mathrm{mg} / \mathrm{ml}$; Sigma-Aldrich, St.Louis, MO, USA). The proteins were separated by sodium dodecyl sulfate-polyacrylamide gel electrophoresis (SDS-PAGE) and transferred onto nitrocellulose membranes. The blots were immunostained with the appropriate primary antibodies followed by secondary antibodies conjugated to horseradish peroxidase. Antibody binding was detected with an enhanced chemiluminescence reagent (Amersham Biosciences, Piscataway, NJ, USA). The primary antibodies against p-Akt $\left(\mathrm{Ser}^{473}\right)$, p-Akt $\left(\mathrm{Thr}^{308}\right)$, Akt, p-mTOR $\left(\mathrm{Ser}^{2448}\right)$, mTOR, p-p70S6K1 $\left(\mathrm{Thr}^{389}\right)$, p70S6K1, PARP, cleaved caspase- 3 and $\beta$-actin were purchased from Cell Signaling Technology, Inc. (Danvers, MA, USA). Bax was purchased from Santa Cruz Biotechnology, Inc. (Santa Cruz, CA, USA). The secondary antibodies were purchased from Amersham Biosciences.

Immunofluorescence and confocal analysis. A549 cells were plated on 18-mm cover glasses in RPMI-1640 medium and incubated for $24 \mathrm{~h}$ so that $70 \%$ confluence was reached. The cells were then incubated in the presence or absence of HS-173 $(1 \mu \mathrm{M})$, washed twice with PBS, and fixed in acetic acid:ethanol solution (1:2) for $5 \mathrm{~min}$ at room temperature. Cells were blocked in $1.5 \%$ horse serum in PBS for $1 \mathrm{~h}$ at room temperature, and then incubated overnight at $4^{\circ} \mathrm{C}$ with primary antibodies including p-Akt, p-mTOR, p-p70S6K, p-cdc2 (Cell Signaling Technology, Inc.), cyclin B1, and p-cdc25C (Santa Cruz Biotechnology, Inc.) in a humidified chamber. After washing twice with PBS, the cells were incubated with fluorescein-labeled secondary antibody (1:100; Dianova, Hamburg, Germany) for $1 \mathrm{~h}$ at room temperature. The cells were also stained with 4,6-diamidino-2-phenylindole (DAPI) to visualize the nuclei. The slides were then washed twice with PBS and covered with DABCO (Sigma-Aldrich) before being viewed with a confocal laser scanning microscope (Olympus, Tokyo, Japan).

DNA fragmentation assay. Terminal deoxynucleotidyl transferase (Tdt) dUTP-mediated nick-end labeling (TUNEL) was performed using the ApopTag Plus Peroxidase In Situ Apoptosis Detection kit (Chemicon, Temecula, CA, USA) according to the manufacturer's instructions. Briefly, A549 cells were plated onto an 18-mm cover glass in RPMI-1640 medium at $\sim 70 \%$ confluence for $24 \mathrm{~h}$ at $37^{\circ} \mathrm{C}$. The cells were then treated with HS-173 $(1 \mu \mathrm{M})$ for $24 \mathrm{~h}$. They were fixed in acetic acid:ethanol solution (1:2) for $5 \mathrm{~min}$ at room temperature and then washed with PBS. Cells were incubated with $20 \mu \mathrm{g} / \mathrm{ml}$ proteinase K (Takara Shuzo Co. Ltd.) for 10-15 min at room temperature and reacted with Tdt enzyme for $60 \mathrm{~min}$ at $37^{\circ} \mathrm{C}$. Cells were then incubated with anti-digoxigenin conjugate at room temperature for $30 \mathrm{~min}$, incubated with diaminobenzidine solution and counterstained with methyl green. Apoptotic cells were observed in cross-section in randomly selected microscopic fields at a final magnification of $x 400$.

In vitro measurement of mitochondrial membrane potential (MMP). MMP was assessed with a JC-1 Mitochondrial Membrane Potential Assay kit (Cayman Chemical Co., Ann Arbor, MI, USA) using 5,5',6,6'-tetrachloro-1,1',3,3'-tetraethylbenzimidazol-carbocyanine iodide (JC-1), which exhibits potential-dependent accumulation in mitochondria. This dye forms J-aggregates under high MMP, causing a shift in fluorescence from green to red. A549 cells were plated on 18-mm 
cover glasses in RPMI-1640 medium and incubated for $24 \mathrm{~h}$. When cells reached $\sim 70 \%$ confluency, cells were then treated with HS-173 $(1 \mu \mathrm{M})$ for $6 \mathrm{~h}$; $100 \mu \mathrm{l}$ of JC-1 solution at a final concentration of $12.5 \mu \mathrm{g} / \mathrm{ml}$ was then added to each well and the plate was incubated for another $15 \mathrm{~min}$ at $37^{\circ} \mathrm{C}$. After washing twice with $\mathrm{PBS}$, the cells were also stained with DAPI to visualize the cell nuclei. The slides were then washed twice with PBS and covered with DABCO before viewing with a confocal laser scanning microscope (Olympus, Tokyo, Japan). Data were represented by the level of the red:green ratio.

Analysis of cytochrome c localization. A549 cells were plated on 18-mm cover glasses in RPMI-1640 medium. When cells reached $\sim 70 \%$ confluency, they were treated with HS-173 $(1 \mu \mathrm{M})$ for $6 \mathrm{~h}$. To label the mitochondria, cells were incubated with $100 \mathrm{nM}$ mitochondrion-specific dye (MitoTracker ${ }^{\circledR}$ Red FM; Molecular Probes Inc., Eugene, OR, USA) for $45 \mathrm{~min}$ at $37^{\circ} \mathrm{C}$ prior to fixation. After washing twice with PBS, cells were fixed in acetic acid:ethanol solution (1:2) for $5 \mathrm{~min}$ at room temperature. Cells were incubated overnight at $4^{\circ} \mathrm{C}$ with cytochrome $c$ antibody (1:20; Santa Cruz Biotechnology, Inc.). After washing twice with PBS, the cells were incubated with mouse fluorescein-labeled secondary antibody (1:50; Dianova). The cells were also stained with DAPI to visualize the nuclei. The slides were then washed twice with PBS and covered with DABCO before viewing with a confocal laser scanning microscope.

Statistical analysis. All data were analyzed using GraphPad Prism (GraphPad software). Data are expressed as the means $\pm \mathrm{SD}$, and P-values $\leq 0.05$ were considered to indicate a statistically significant result.

\section{Results}

HS-173 inhibits cell proliferation. In our previous study, HS-173 demonstrated a high binding affinity for the ATP-binding site of PI3K $\alpha$ (Fig. 1A) and antitumor activity against breast cancer through inhibition of the PI3K/Akt/ mTOR pathway (17). This pathway is closely associated with the development and progression of NSCLC as well as breast cancer (18). To assess the effect of HS-173 on NSCLC proliferation, 3 NSCLC cell lines, A549, H1299 and NCI-H596, were exposed to various concentrations of HS-173 for $48 \mathrm{~h}$ and then analyzed by MTT assay. As shown in Fig. 1B, treatment with HS-173 resulted in a dose-dependent reduction in viable cancer cells. The $\mathrm{IC}_{50}$ of HS-173 was 1,10 and $0.95 \mu \mathrm{M}$ in A549, H1299 and NCI-H596 cells, respectively.

HS-173 inhibits the PI3K-Akt-mTOR pathway. To assess the effect of HS-173 on intracellular signaling in NSCLC, A549 cells were exposed to various concentrations of HS-173 in vitro for $2 \mathrm{~h}$, lysed and analyzed by western blotting. As shown in Fig. 2A, the phosphorylation of Akt, mTOR and p70S6K1 was effectively suppressed, indicating complete suppression of the PI3K pathway. Similar to the results of the western analysis, confocal microscopy data showed that HS-173 also strongly suppressed phosphorylation of Akt, mTOR and p70S6K1 (Fig. 2B).
A<smiles>CCOC(=O)c1cnc2ccc(-c3cncc(NS(=O)(=O)c4ccccc4)c3)cn12</smiles>

HS-173

Ethyl 6-(5-(phenylsulfonamido)pyridin-3yl)imidazo[1,2-a]pyridine-3-carboxylate

B

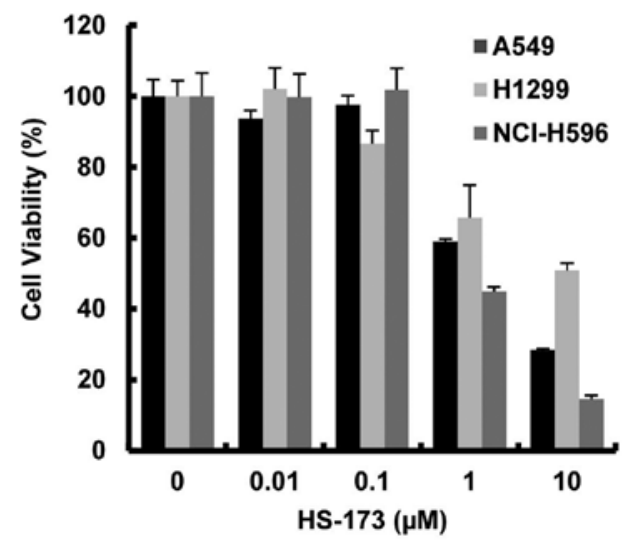

Figure 1. Chemical structure of HS-173 and the effect of HS-173 on the proliferation of human non-small cell lung cancer (NSCLC) cells. (A) Chemical structure of ethyl 6-(5-(phenylsulfonamido)pyridin-3-yl)imidazo[1,2-a] pyridine-3-carboxylate (HS-173). (B) The cytotoxic effects of HS-173 on human NSCLC cell lines (A549, H1299 and NCI-H596). Inhibitory effect of HS-173 on NSCLC cell proliferation was assessed with an MTT assay. Results are expressed as the percent cell proliferation relative to the control. Data are expressed as the means \pm SD from triplicate wells.

HS-173 causes cell cycle arrest. To assess the effect of HS-173 on the cell cycle, A549 cells were exposed to various concentrations of HS-173 for $12 \mathrm{~h}$, then fixed with ice-ethanol and analyzed using flow cytometry. As shown in Fig. 3A, HS-173 induced cell cycle arrest at the $\mathrm{G}_{2} / \mathrm{M}$ phase in a dose-dependent manner. To further clarify the mechanism of HS-173-induced cell cycle arrest at the $\mathrm{G}_{2} / \mathrm{M}$ phase, we investigated the expression of proteins related to the $\mathrm{G}_{2} / \mathrm{M}$ checkpoint using fluorescence confocal microscopy. HS-173 triggered a decrease in expression of cyclin B1, as well as an increase in phosphorylation of cdc2 and cdc25C (Fig. 3B).

HS-173 induces apoptosis. To determine whether the effects of HS-173, including inhibition of the PI3K/Akt/mTOR pathway and cell cycle arrest, are due to the induction of apoptosis, we analyzed the ability of HS-173 to induce apoptosis of A549 lung cancer cells. First, apoptosis by HS-173 was confirmed by DNA fragmentation assay (Fig. 4A). As a result, treatment with $1 \mu \mathrm{M}$ HS-173 for $24 \mathrm{~h}$ increased TUNEL-positive cells. In addition, to study the effect of HS-173 on MMP, the drug-treated cells were exposed to the fluorescent cationic dye JC-1. As shown in Fig. 4B, treatment with HS-173 induced the 
A

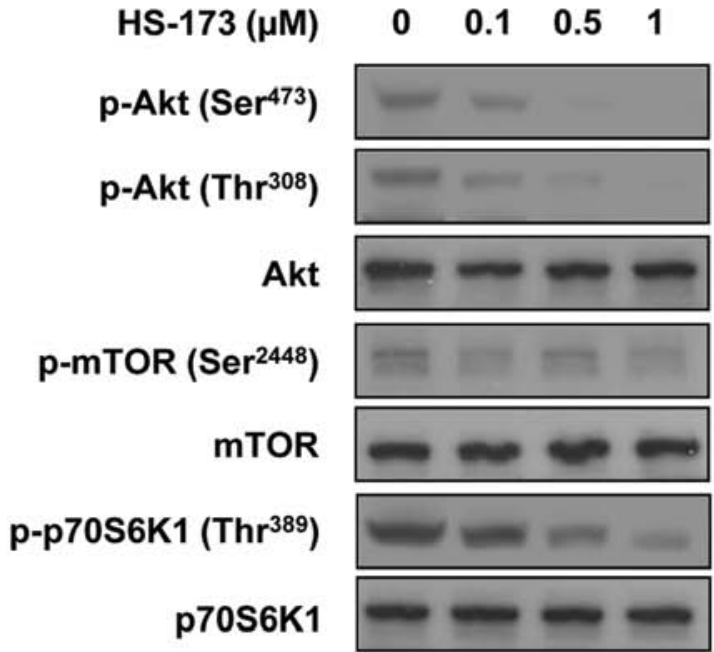

B
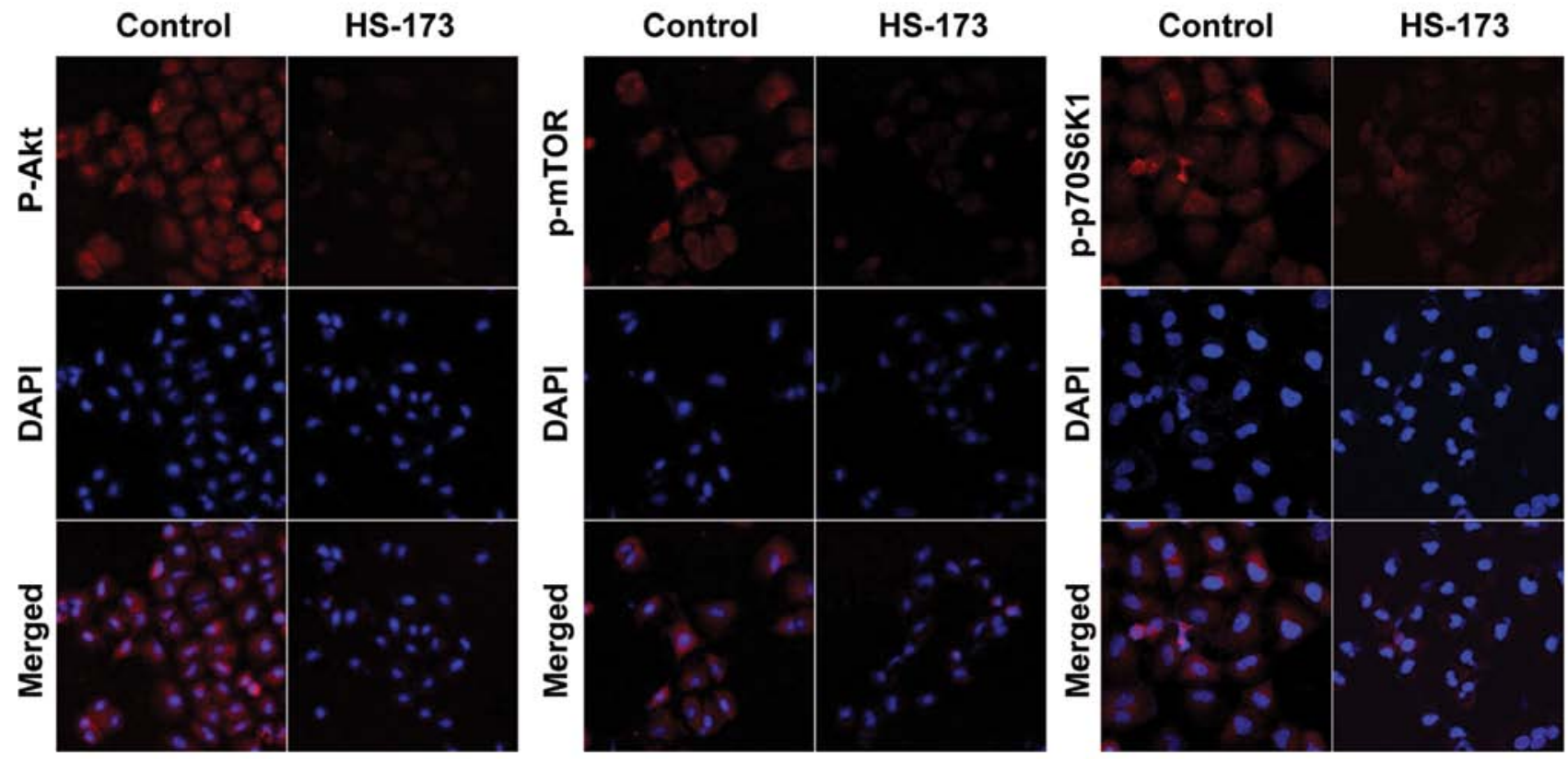

Figure 2. Effect of HS-173 on PI3K/Akt/mTOR signaling in A549 cells. (A) Cells were treated with various concentrations (0.1-1 $\mu \mathrm{M})$ of HS-173 for $2 \mathrm{~h}$. The protein expression of Akt, mTOR and p70S6K1 as well as the phosphorylated forms of these molecules was determined by western blotting. (B) Cells were treated with $1 \mu \mathrm{M}$ HS-173 for $2 \mathrm{~h}$. p-Akt, p-mTOR and p-p70S6K1 were detected by immunofluorescence. DAPI was used to visualize the cell nuclei. Images were captured at $x 400$ magnification. A representative image from 3 independent experiments is shown.

loss of MMP 5-fold when compared to that of the controls. This change in MMP can trigger the release of mitochondrial cytochrome $c$ into the cytosol, a hallmark of intrinsic pathwaymediated apoptosis. Therefore, we investigated the release of cytochrome $c$ by HS-173 in A549 lung cancer cells. As shown in Fig. 4C, we observed that treatment of HS-173 synergistically increased cytochrome $c$ release along with a concomitant decrease in the-co-localization of cytochrome $c$ to the mitochondria. We also examined the expression of proteins related to apoptosis by western blotting. As expected, HS-173 caused increased expression of cleaved caspase-3, PARP and Bax in a dose-dependent manner (Fig. 4D). Overall, these data suggest that HS-173 causes apoptosis by directly affecting mitochondria and activating caspases.

\section{Discussion}

Since more than $60 \%$ of NSCLC cases express EGFR, the treatment modalities for NSCLC have involved the development of EGFR TKIs. Two EGFR TKIs, gefitinib and erlotinib, have been approved by the FDA for the treatment of locally advanced or metastatic NSCLC that has failed at least one prior chemotherapy regimen. However, they are only effective in cancer patients with mutated and overactive EGFR. It has been reported that patients with lung cancer usually develop drug-resistance by unknown mechanisms (19). Therefore, current treatments of lung cancer are not satisfactory, with a mean survival of $<1$ year for advanced lung cancer patients, regardless of treatment regimen (20). 
A
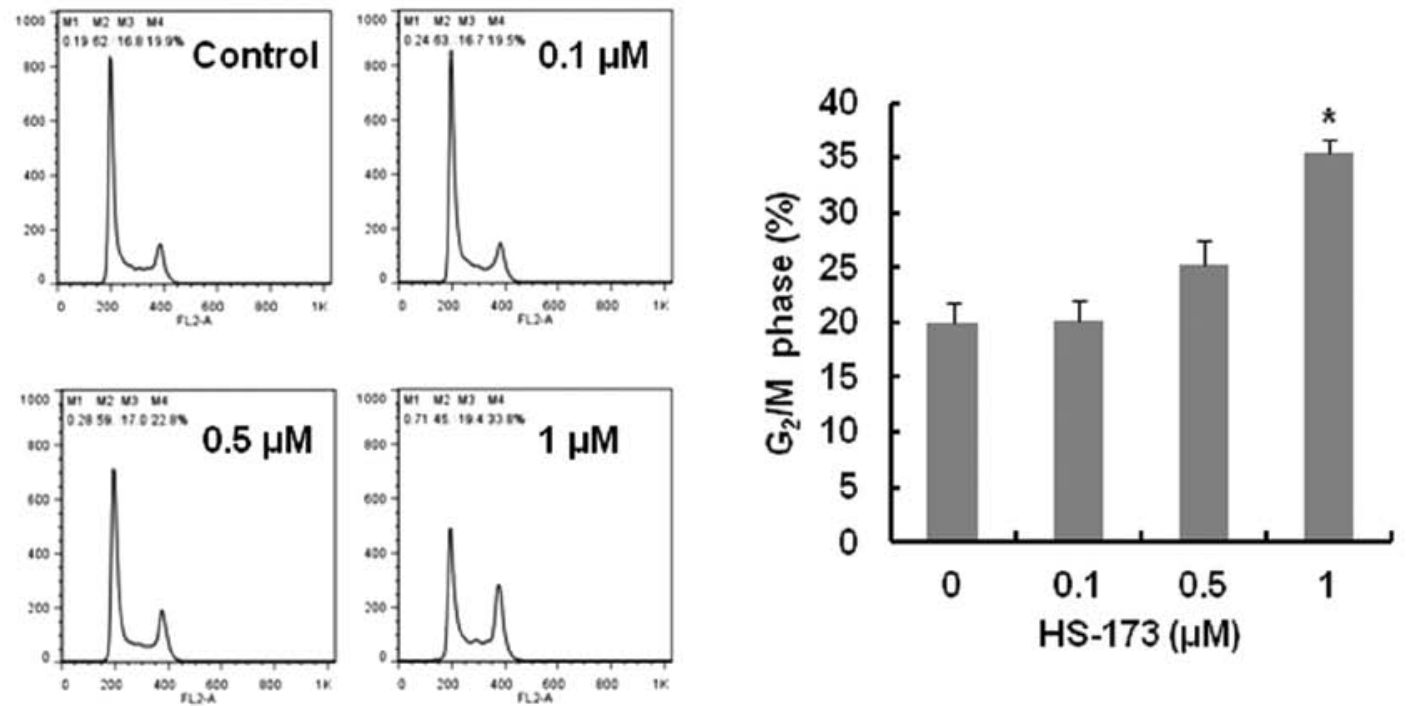

B

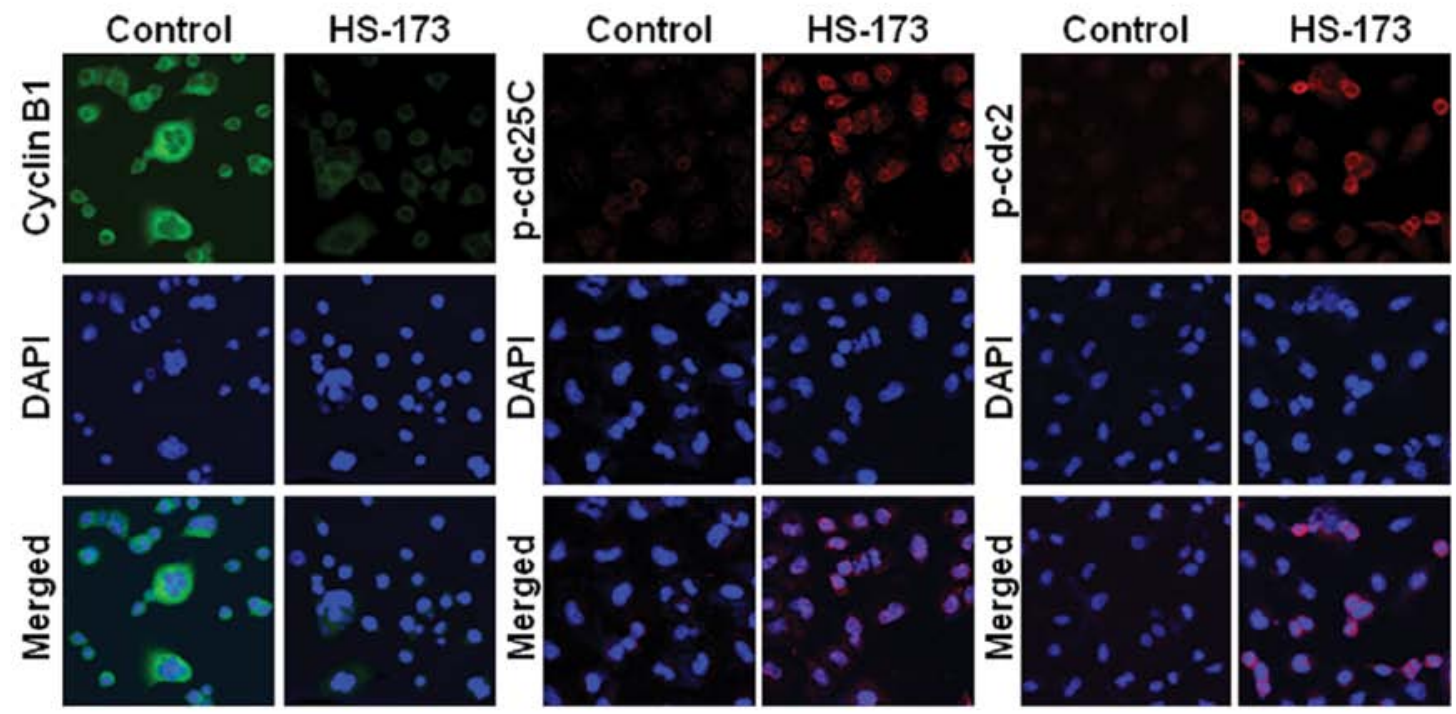

Figure 3. Effect of HS-173 on the cell cycle in A549 cells. (A) A549 cells were treated with HS-173 ( $0,0.1,0.5$ and $1 \mu \mathrm{M})$ for $12 \mathrm{~h}$, stained with propidium iodide (PI) and assessed by flow cytometry. $\mathrm{M}_{1}$, sub- $\mathrm{G}_{1} ; \mathrm{M}_{2}, \mathrm{G}_{0} / \mathrm{G}_{1} ; \mathrm{M}_{3}, \mathrm{~S} ; \mathrm{M}_{4}, \mathrm{G}_{2} / \mathrm{M}$. Quantitation of the cell distribution in the $\mathrm{G}_{2} / \mathrm{M}$ phase of the cell cycle. Data from 3 independent experiments are presented as means \pm SD. (B) The expression of cyclin B1, p-cdc25C and p-cdc2 was detected by immunofluorescence in cells treated with $1 \mu \mathrm{M}$ HS-173 for $12 \mathrm{~h}$. Images were captured at $\mathrm{x} 400$ magnification. Representative images from 3 independent experiments are shown. ${ }^{*} \mathrm{P}<0.05$, compared to control.

EGFR plays a pivotal role in lung cancer by activating several oncogenic signaling pathways. Among these, the $\mathrm{PI} 3 \mathrm{~K} / \mathrm{Akt} / \mathrm{mTOR}$ pathway has been intensely investigated for its pivotal role in regulating cell proliferation, survival and metabolism. Therefore, inhibition of EGFR tyrosine kinase by gefitinib leads to the suppression of the PI3K pathway. Recently, several inhibitors targeting the PI3K pathway have been developed and are being evaluated in preclinical studies and early clinical trials. These include pan-PI3K and isoform-specific PI3K inhibitors, dual PI3K-mTOR inhibitors, mTOR catalytic site inhibitors and AKT inhibitors (21-24). In the development of potent PI3K inhibitors, we screened numerous compounds and finally developed a novel compound, HS-173 (17). HS-173 demonstrated antitumor activity by inhibiting the PI3K pathway in liver and breast cancer (16). In the present study, we investigated the anticancer effect of HS-173 and its mechanism of action in NSCLC cell lines.

Notably, although the PI3K pathway is activated in NSCLC cell lines, Akt activity is selectively reduced in response to gefitinib in NSCLC cell lines whose growth is inhibited by gefitinib, while its activity is not reduced in cells resistant to gefitinib (12). Our study showed that HS-173 inhibited the growth of NSCLC cell lines which are resistant to gefitinib as well as the PI3K pathway. This supports the concept that the inhibition of the PI3K pathway can overcome the resistance of gefitinib in NSCLC.

In the present study, the inhibition of the PI3K/Akt/mTOR pathway by HS-173 led to cell cycle arrest during the $G_{2} / M$ phase. In most mammalian cells, mitosis is triggered by activation of the cyclin-dependent kinase cdc2. Activation of 
A
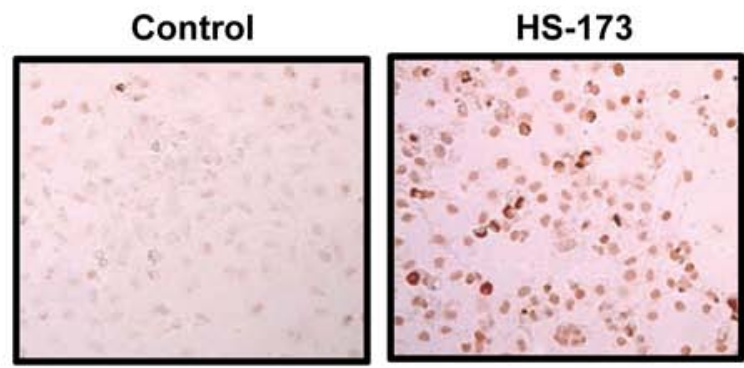

B

Control
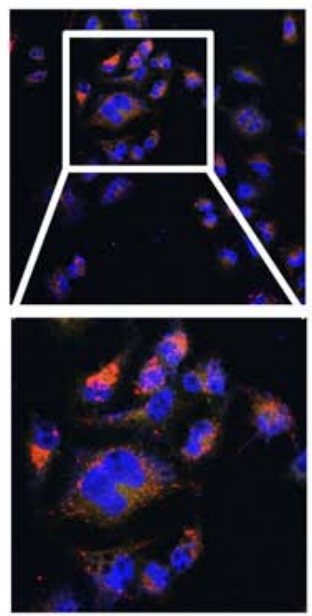

C

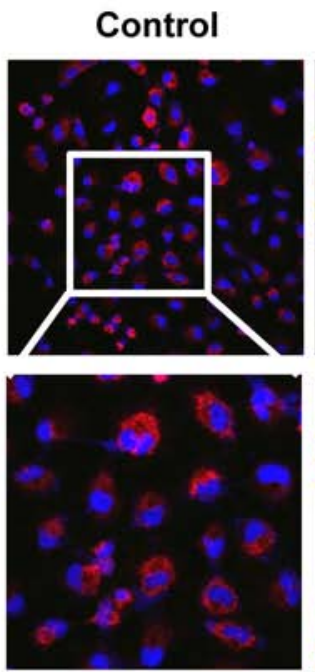

HS-173
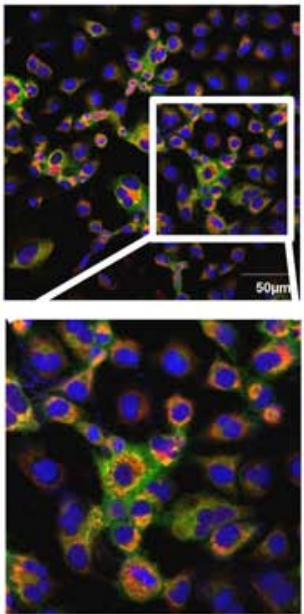

HS-173
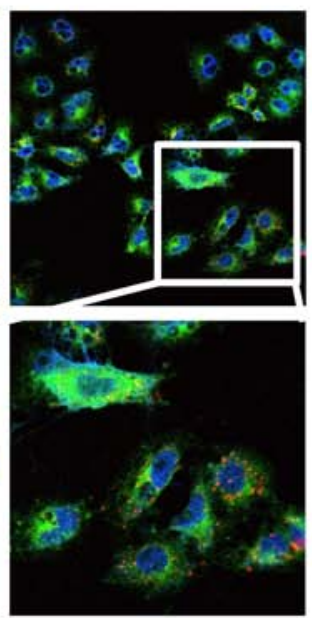
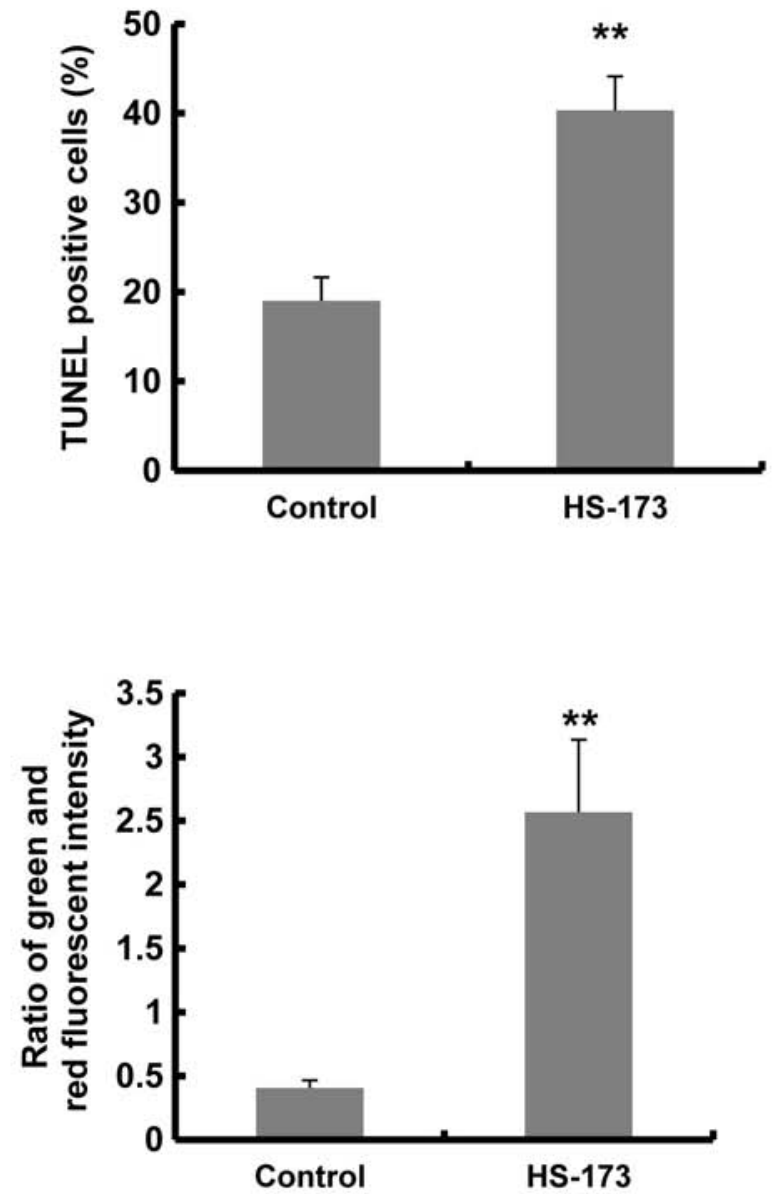

D

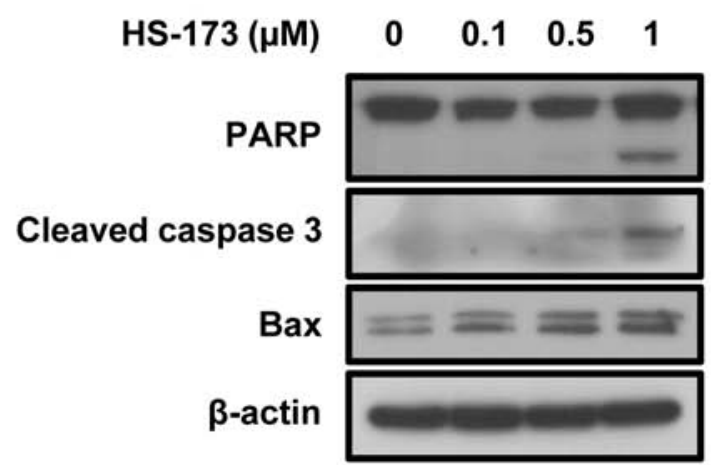

Figure 4. Effect of HS-173 on the apoptosis of A549 cells. (A) DNA fragmentation was assessed by TUNEL assay. (B) MMP was determined by JC-1 staining. Loss of MMP (green) was detected in HS-173-treated cells. (C) Release of cytochrome $c$ by HS-173. Localization of cytochrome $c$ in the cytosol by HS-173 was observed. (D) Expression of apoptosis-related protein was determined by western blotting in A549 cells treated with HS-173. ${ }^{* *} \mathrm{P}<0.01$, compared to control.

this kinase is a multistep process that starts with the binding of cyclin B1 (25). Phosphorylated and inhibited cdc2 is dephosphorylated by cdc25C phosphatase, which is also phosphorylated and inhibited by Chk2 (26). It has been reported that suppression of AKT enhances the activation of Chk2, resulting in increased inactive phosphorylation of cdc25C and cdc2 (27). In order to investigate whether the blockade of $\mathrm{G}_{2} / \mathrm{M}$ phase transition induced by HS-173 was due to the modulation of these regulatory proteins, we evaluated the expression levels of cyclin B1, p-cdc25C and p-cdc2. Phosphorylation of cdc2 at the Tyr15 residue is involved in the arrest of dividing cells at the $\mathrm{G}_{2} / \mathrm{M}$ phase transition (28). In the present study, treatment with HS-173 decreased the level of cyclin B1 and increased p-cdc25C and p-cdc2. The $\mathrm{G}_{2} / \mathrm{M}$ checkpoint is an important 
cell cycle checkpoint in eukaryotic organisms ranging from yeast to mammals (29). DNA damage and inhibition of the PI3K pathway by anticancer drugs, cytotoxic methylating agents and radiation can promote cell cycle arrest at the $\mathrm{G}_{2}$ phase (30). In addition, inhibition of protein synthesis during the $G_{2}$ phase prevents the cell from undergoing mitosis. PI3K signaling has been reported to contribute to protein synthesis through the PI3K/Akt/mTOR pathway (31). Therefore, DNA damage and inhibition of protein synthesis via the inhibition of the PI3K/ Akt/mTOR pathway by HS-173 may lead to $\mathrm{G}_{2} / \mathrm{M}$ arrest.

The PI3K/Akt/mTOR pathway is involved in cell survival. Disruption of MMP induces the release of cytochrome $c$ from mitochondria and is associated with the activation of caspase-3. In addition, MMP can be regulated by $\mathrm{Bcl}-2$, which is known to play a role in maintaining MMP by binding to mitochondria. In contrast, Bax, a pro-apoptotic Bcl-2 family member, translocates to the mitochondria and perturbs MMP (32). In the present study, HS-173 disrupted the MMP of A549 cells, and increased the release of cytochrome $c$, the level of cleaved capase- 3 and Bax. These data suggest that apoptosis induced by HS-173 may be mediated through activation of the intrinsic apoptotic pathway.

Our present study demonstrated that disruption of the PI3K/Akt/mROR pathway or inhibition of PI3K activity by the specific inhibitor, HS-173, significantly sensitized NSCLC cells to apoptosis induced by chemotherapeutics in vitro. Our findings suggest that HS-173 may be used to treat NSCLC cases resistant or sensitive to EGFR TKIs.

\section{Acknowledgements}

This study was supported by the Korean Health Technology R\&D Project (A120266 and A110862) and the National Research Foundation of Korea (NRF) funded by the Ministry of Education, Science and Technology (NRF-20120002988, 2012R1A2A2A01045602 and 2012-0003009) and Inha University Grant.

\section{References}

1. Jemal A, Bray F, Center MM, Ferlay J, Ward E and Forman D Global cancer statistics. CA Cancer J Clin 61: 69-90, 2011.

2. Roggli VL, Vollmer RT, Greenberg SD, McGavran MH, Spjut HJ and Yesner R: Lung cancer heterogeneity: a blinded and randomized study of 100 consecutive cases. Hum Pathol 16: 569-579, 1985.

3. Kuwabara K, Matsuda S, Fushimi K, et al: Differences in practice patterns and costs between small cell and non-small cell lung cancer patients in Japan. Tohoku J Exp Med 217: 29-35, 2009.

4. Gazdar AF: Epidermal growth factor receptor inhibition in lung cancer: the evolving role of individualized therapy. Cancer Metastasis Rev 29: 37-48, 2010.

5. Shepherd FA, Rodrigues Pereira J, Ciuleanu T, et al: Erlotinib in previously treated non-small-cell lung cancer. N Engl J Med 353: 123-132, 2005.

6. Pao W, Miller VA, Politi KA, et al: Acquired resistance of lung adenocarcinomas to gefitinib or erlotinib is associated with a second mutation in the EGFR kinase domain. PLoS Med 2: e73, 2005.

7. Vanhaesebroeck B, Guillermet-Guibert J, Graupera M and Bilanges B: The emerging mechanisms of isoform-specific PI3K signalling. Nat Rev Mol Cell Biol 11: 329-341, 2010.

8. Cantley LC: The phosphoinositide 3-kinase pathway. Science 296: 1655-1657, 2002

9. Luo J, Manning BD and Cantley LC: Targeting the PI3K-Akt pathway in human cancer: rationale and promise. Cancer Cell 4 : 257-262, 2003
10. Engelman JA: Targeting PI3K signalling in cancer: opportunities, challenges and limitations. Nat Rev Cancer 9: 550-562, 2009.

11. Janmaat ML, Kruyt FA, Rodriguez JA and Giaccone G: Response to epidermal growth factor receptor inhibitors in non-small cell lung cancer cells: limited antiproliferative effects and absence of apoptosis associated with persistent activity of extracellular signal-regulated kinase or Akt kinase pathways. Clin Cancer Res 9: 2316-2326, 2003.

12. Engelman JA, Jänne PA, Mermel C, et al: ErbB-3 mediates phosphoinositide 3-kinase activity in gefitinib-sensitive non-small cell lung cancer cell lines. Proc Natl Acad Sci USA 102: 3788-3793, 2005.

13. Yamasaki F, Johansen MJ, Zhang D, et al: Acquired resistance to erlotinib in A-431 epidermoid cancer cells requires down-regulation of MMAC1/PTEN and up-regulation of phosphorylated Akt. Cancer Res 67: 5779-5788, 2007.

14. Engelman JA, Chen L, Tan X, et al: Effective use of PI3K and MEK inhibitors to treat mutant Kras G12D and PIK3CA H1047R murine lung cancers. Nat Med 14: 1351-1356, 2008.

15. Samuels Y, Wang Z, Bardelli A, et al: High frequency of mutations of the PIK3CA gene in human cancers. Science 304: $554,2004$.

16. Lee H, Jung KH, Jeong Y, Hong S and Hong SS: HS-173, a novel phosphatidylinositol 3-kinase (PI3K) inhibitor, has anti-tumor activity through promoting apoptosis and inhibiting angiogenesis. Cancer Lett 328: 152-159, 2013.

17. Kim O, Jeong Y, Lee H, Hong SS and Hong S: Design and synthesis of imidazopyridine analogues as inhibitors of phosphoinositide 3-kinase signaling and angiogenesis. J Med Chem 54: 2455-2466, 2011.

18. Alvarez M, Roman E, Santos ES and Raez LE: New targets for non-small-cell lung cancer therapy. Expert Rev Anticancer Ther 7: 1423-1437, 2007.

19. Pao W, Miller V, Zakowski M, et al: EGF receptor gene mutations are common in lung cancers from 'never smokers' and are associated with sensitivity of tumors to gefitinib and erlotinib. Proc Natl Acad Sci USA 101: 13306-13311, 2004.

20. Bast RC, Kufe DW, Pollock RE, et al (eds): Cancer of the lung. In: Holland-Frei Cancer Medicine. 5th edition. BC Decker Publishing Inc., Hamilton, ON, 2000.

21. Yang L, Dan HC, Sun M, et al: Akt/protein kinase B signaling inhibitor-2, a selective small molecule inhibitor of Akt signaling with antitumor activity in cancer cells overexpressing Akt. Cancer Res 64: 4394-4399, 2004.

22. Workman P: Inhibiting the phosphoinositide 3-kinase pathway for cancer treatment. Biochem Soc Trans 32: 393-396, 2004.

23. Schultz RM, Merriman RL, Andis SL, et al: In vitro and in vivo antitumor activity of the phosphatidylinositol-3-kinase inhibitor, wortmannin. Anticancer Res 15: 1135-1139, 1995.

24. Rowinsky EK: Targeting the molecular target of rapamycin (mTOR). Curr Opin Oncol 16: 564-575, 2004.

25. Lindqvist A, Rodriguez-Bravo V and Medema RH: The decision to enter mitosis: feedback and redundancy in the mitotic entry network. J Cell Biol 185: 193-202, 2009.

26. Tyagi A, Singh RP, Agarwal C, Siriwardana S, Sclafani RA and Agarwal R: Resveratrol causes Cdc2-tyr15 phosphorylation via ATM/ATR-Chk1/2-Cdc25C pathway as a central mechanism for $\mathrm{S}$ phase arrest in human ovarian carcinoma Ovcar-3 cells. Carcinogenesis 26: 1978-1987, 2005.

27. Kuo PL, Hsu YL and Cho CY: Plumbagin induces G2-M arrest and autophagy by inhibiting the AKT/mammalian target of rapamycin pathway in breast cancer cells. Mol Cancer Ther 5: 3209-3221, 2006.

28. O'Farrell PH: Triggering the all-or-nothing switch into mitosis. Trends Cell Biol 11: 512-519, 2001.

29. Cuddihy AR and O'Connell MJ: Cell-cycle responses to DNA damage in G2. Int Rev Cytol 222: 99-140, 2003.

30. Hirose Y, Katayama M, Mirzoeva OK, Berger MS and Pieper RO: Akt activation suppresses Chk2-mediated, methylating agentinduced G2 arrest and protects from temozolomide-induced mitotic catastrophe and cellular senescence. Cancer Res 65: 4861-4869, 2005.

31. Wang $X$ and Proud CG: The mTOR pathway in the control of protein synthesis. Physiology (Bethesda) 21: 362-369, 2006.

32. Ashe PC and Berry MD: Apoptotic signaling cascades. Prog Neuropsychopharmacol Biol Psychiatry 27: 199-214, 2003. 